\title{
Transgenerational Consequences of Plant Responses to Herbivory: An Adaptive Maternal Effect?
}

\begin{abstract}
Anurag A. Agrawal
Department of Entomology and Center for Population Biology, University of California, Davis, California 95616-8584
\end{abstract}

Submitted June 14, 1999; Accepted December 21, 2000

A BST RACT: Herbivory has many effects on plants, ranging from shifts in primary processes such as photosynthesis, growth, and phenology to effects on defense against subsequent herbivores and other species interactions. In this study, I investigated the effects of herbivory on seed and seedling characteristics of several families of wild radish (Raphanus raphanistrum) to test the hypothesis that herbivory may affect the quality of offspring and the resistance of offspring to plant parasites. Transgenerational effects of herbivory may represent adaptive maternal effects or factors that constrain or amplify natural selection on progeny. Caterpillar (Pieris rapae) herbivory to greenhouse-grown plants caused plants in some families to produce smaller seeds and those in other families to produce larger seeds compared with undamaged controls. Seed mass was positively associated with probability of emergence in the field. The number of setose trichomes, a putative plant defense, was higher in the progeny of damaged plants in some families and lower in the progeny of damaged plants in other families. In a field experiment, plant families varied in their resistance to several herbivores and pathogens as well as in growth rate and time to flowering. Seeds from damaged parent plants were more likely to become infested with a plant virus. Although herbivory on maternal plants did not directly affect interactions of offspring with other plant parasites, seed mass influenced plant resistance to several attackers. Thus, herbivory affected seed characters, which mediated interactions between plants and their parasites. Finally, irrespective of seed mass, herbivory on maternal plants influenced components of progeny fitness, which was dependent on plant family. Natural selection may act on plant responses to herbivory that affect seedling-parasite interactions and, ultimately, fitness.

Keywords: adaptive plasticity, induced defense, norm of reaction, plant-insect interactions, phenotypic plasticity, seed mass.

\footnotetext{
* Present address: Department of Botany, University of Toronto, Toronto, Ontario M5S 3B2, Canada; e-mail: agrawal@botany.utoronto.ca.

Am. Nat. 2001. Vol. 157, pp. 555-569. (C) 2001 by The University of Chicago. 0003-0147/2001/15705-0007\$03.00. All rights reserved.
}

Nearly every plant is subject to parasitism by herbivores, and in many cases herbivory reduces plant fitness. Thus, herbivory may select for defenses that reduce herbivory or its consequences for the plant (Marquis 1992). Plant defenses against herbivores can take many forms, including toxic chemicals, antinutritive compounds, and physical barriers to attack. Furthermore, such defenses can be expressed constitutively (all of the time) or induced following attack by herbivores. In plants that exhibit facultative, or inducible, defenses, leaf damage can cause induction of resistance mechanisms in roots, shoots, and flowers of the plant (Karban and Baldwin 1997). Such induction can be adaptive in that it increases the fitness of plants in the presence of herbivores (Agrawal 1998).

In addition to the effects of herbivory on subsequent plant resistance, herbivory necessarily causes a reduction in leaf area and resources for the plant. Reductions in resources available to the plant caused by herbivory can decrease survivorship, growth, floral characters, pollen number and size, and seed number and mass (Crawley and Nachapong 1985; Marquis 1992; Quesada et al. 1995; Mutikainen and Delph 1996; Maron 1997; Strauss 1997; Bigger and Marvier 1998; Agrawal et al. 1999a; but see Strauss and Agrawal 1999 for a review of plant tolerance to herbivory). Thus, herbivory can have direct effects on the fitness of a host plant through effects on the number and/or vigor of the plant's offspring. I propose that herbivory may also have a delayed effect on the fitness of a plant by altering the resistance of its offspring to herbivores and pathogens. Because seeds develop in the maternal environment, and the maternal environment may predict the offsprings' environmental conditions, transgenerational effects of herbivory may provide a mechanism for adaptive maternal effects.

Traditionally, maternal environmental effects on phenotypes of progeny have been measured in terms of the resources parents have available and can invest in offspring (Roach and Wulff 1987; Aarssen and Burton 1990; Schmitt et al. 1992; Rossiter 1996). For example, plants grown with mycorrhizal mutualists were larger and produced more vigorous offspring compared with plants without mycor- 
rhizal associates (Heppell et al. 1998). Such maternal effects may be largely due to increased resource acquisition via mycorrhizal associates and, although adaptive, may reflect passive transmission of nutrients from mother to offspring. Alternatively, maternal effects can also take the form of apparently more "active" investments in offspring that may not be based solely on limiting nutrients (Dussourd et al. 1988; Mousseau and Dingle 1991; Fox et al. 1997). For example, diabroticine beetles feeding on plants containing cucurbitacins (secondary compounds) allocate these compounds to their eggs. Male beetles provide cucurbitacin-rich "nuptial gifts" to females that are then incorporated into the eggs of the recipient (Tallamy et al. 2000). Beetle eggs containing cucurbitacins are protected from predation and parasitism by insect predators, entomopathogenic nematodes, and fungal entomopathogens (Barbercheck et al. 1995; Tallamy et al. 1998). Plants can also endow defenses to their progeny. Plants that produce defensive compounds in their roots, shoots, and reproductive structures can potentially incorporate such defenses in their fruits and seeds. In fact, fruits and seeds are often the most protected plant tissues (Janzen 1971; Zangerl and Rutledge 1996; Cipollini and Levey 1997).

I examined the effects of herbivory to parents on resistance characters of their offspring. In other words, I asked if herbivory and plant responses associated with herbivory could cause transgenerational effects, whereby offspring of damaged plants are more or less resistant to herbivores than offspring of undamaged plants. Several lines of evidence suggest that transgenerational inducible defenses are possible in plants. First, chemical induction has been reported in the reproductive structures of plants (Baldwin and Karb 1995; Zangerl and Rutledge 1996; Karban and Baldwin 1997). Many plant species in the Brassicaceae (the subject of this study) induce high concentrations of putatively defensive glucosinolates in plants attacked by herbivores compared with controls (Koritsas et al. 1991; Bodnaryk 1992; Bodnaryk and Rymerson 1994; Siemens and Mitchell-Olds 1998; Agrawal et al. 1999a). Moreover, Brassica plants infested with herbivores grown in the field and greenhouse produced seeds containing higher concentrations of glucosinolates than control plants that were not infested (Lammerink et al. 1984). In addition, recent work has shown that inducible defenses can be activated at the seed germination stage using natural chemical elicitors of induced resistance (Arimoto et al. 1991; Siegrist et al. 1997; Jensen et al. 1998). Thus, if herbivory results in the allocation of defensive compounds to ovules before seed development is complete, then offspring from damaged plants may be better defended than offspring from undamaged plants. Alternatively, defense genes induced by herbivory (e.g., Ryan 1990; Zhu et al. 1996; Glazebrook et al. 1997) may be activated in repro- ductive parts, including ovules, and this may render offspring from damaged plants "preinduced" compared with offspring from undamaged plants.

Transgenerational induction is a form of plasticity in plant defense. It is only likely to be adaptive if the herbivore environment in one generation accurately predicts the herbivore environment in subsequent generations (Mousseau and Fox 1998; Karban et al. 1999). This assumption may be met for plants in which seeds are held on the plant, seeds are not dispersed very far, or for situations in which herbivores exhibit site fidelity or cyclical population dynamics. In other words, transgenerational induced plant defenses may benefit plants in situations where plants that are under herbivore attack will have offspring that experience similar levels and types of herbivory.

Many aspects of the evolutionary ecology of induced responses to herbivory have been well studied in wild radish plants. For example, both trichomes and indole glucosinolates increase following plant attack by pierid caterpillars (Agrawal 1999b; Agrawal et al. 1999a). In field experiments with natural levels of attack, induced plants were protected from several herbivores and produced $60 \%$ more seed than uninduced controls (Agrawal 1998). In environments without herbivores, induction was associated with costs, although mostly in components of male fitness (Agrawal et al. 1999a). Such phenotypic benefits of induction in the presence of herbivores and costs in the absence of herbivores indicate that induced plant responses are a form of adaptive plasticity (sensu Dudley and Schmitt 1996). This study sought to extend our understanding of plant responses to herbivory, beyond the generation that received herbivory, to examine effects of herbivory on the progeny of damaged plants. The effects of herbivory on the resistance and reproductive success of offspring were examined in wild radish plants of known maternal origin. Specifically, I asked three questions. First, does herbivory affect the seed mass of wild radish? Second, does herbivory on maternal plants and seed mass affect the resistance of offspring to herbivores and pathogens? And finally, does herbivory on maternal plants and seed mass affect the growth, phenology, and fruit production of the progeny?

\section{Material and Methods}

\section{Study System}

Raphanus raphanistrum (Brassicaceae) is a cosmopolitan, self-incompatible annual plant found in disturbed sites. In northern California, where this study was conducted, wild radish plants germinate in the late winter though early spring (December-February), flower through late spring (February-June), and produce indehiscent seeds by early summer (May-July). Generalist and specialist folivores of 
wild radish include various caterpillars, aphids, beetles, and mollusks. Seed predators of wild radish include those that feed on immature seed pods (Pieris rapae larvae, flea beetles, and stink bugs) and those that feed on mature seeds (birds and possibly ants; S. Courtney, personal communication).

\section{Effects of Herbivory on Seed and Seedling Characteristics}

I used $R$. raphanistrum seeds from a second generation of untreated, greenhouse-grown plants (see fig. 1 for experimental design) for this experiment in order to equalize maternal environment effects between families. I collected approximately 10 seeds from each of 13 maternal families (full or half sibs). Plants were grown in a greenhouse in 0.8-L pots in Sunshine Soil Mix \#1 (Sun Grow Horticulture, Bellevue, Wash.). Natural light was augmented with sodium vapor lights on a $16 \mathrm{~L}: 8 \mathrm{D}$ cycle. Pots were randomly placed in trays (approximately 8 pots per tray) and were watered from below using automated emitters. Each pot received one dose of $0.3 \mathrm{~g}$ of $17 \mathrm{~N}: 9 \mathrm{P}: 13 \mathrm{~K}$ Osmocote slow-release microfertilizer (Scotts-Sierra, Marysville, Ohio). To minimize the effects of temperature and light heterogeneity within the greenhouse, each tray was moved (both within and among rows) every other day for the duration of the experiment. At the four-leaf stage, each plant was randomly assigned to one of two treatments (three to five plants per treatment per family): unmanipulated controls and $50 \%$ of each leaf consumed by a caged $P$. rapae larva, a natural herbivore of $R$. raphanistrum. In natural populations, approximately $15 \%$ of plants have $50 \%$ of their leaf tissue removed by herbivores (S. Y. Strauss, personal communication). Caterpillars were contained in small "clip cages" made from the tops of $5-\mathrm{cm}$ petri dishes. Two petri dish tops were used as the cage and were secured using a bent hair clip glued to the top and bottom of the cage. A wooden stake was used to support the cage structure so as not to weigh down the leaves.

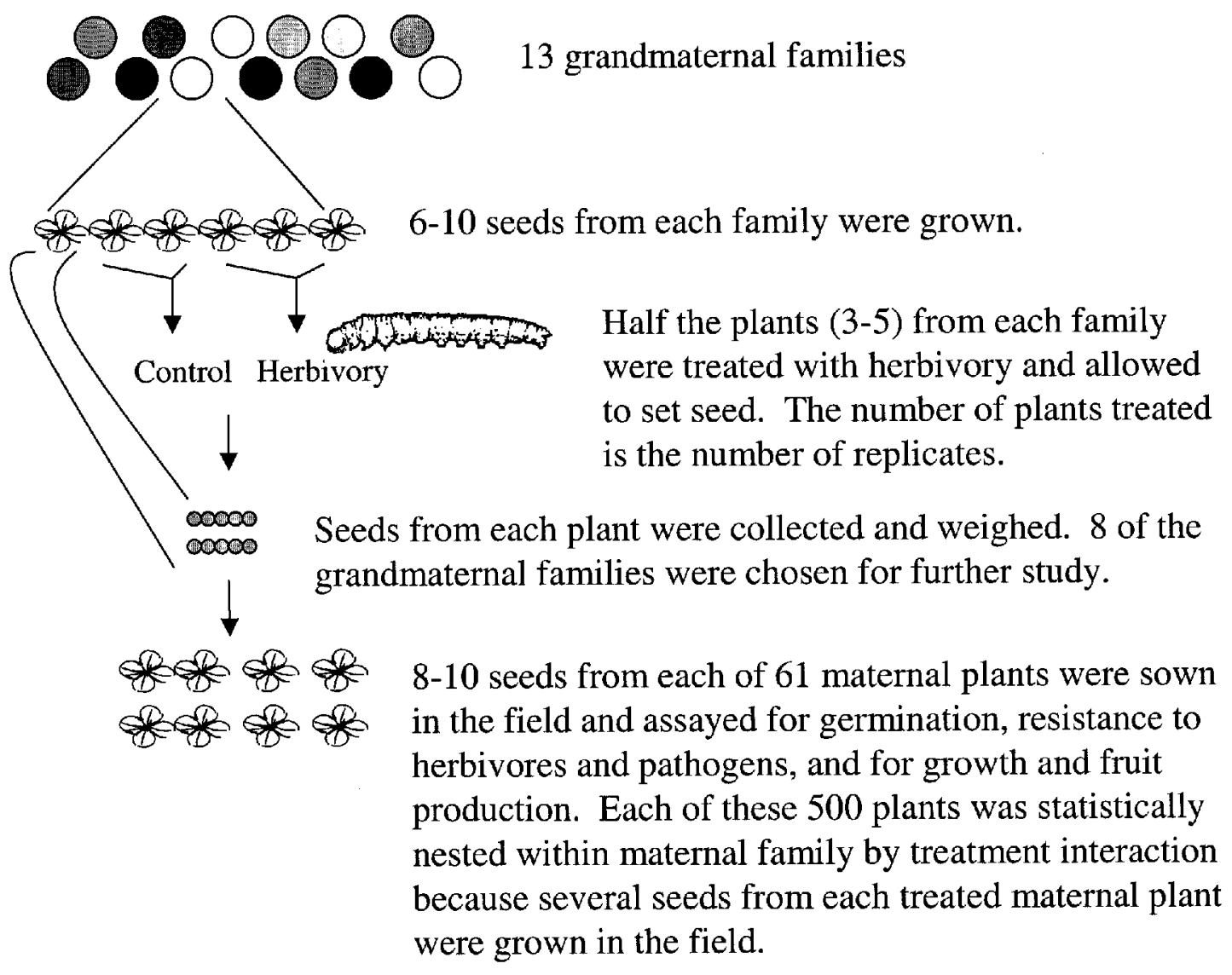

Figure 1: Schematic diagram of the experimental design used in this experiment. The final set of seeds that was sown in the field was from 61 maternal plants within eight grandmaternal families. 
Cages were placed adjacent to the midrib of a leaf, and caterpillars fed on tissue within the cages. After all leaf area within the cage was eaten, I moved the cage along the leaf until the area on one side of the midrib was entirely consumed. The caterpillar herbivory treatment was maintained throughout the growth of the plant. In other experiments, wild radish plants with empty clip cages produced the same number of flowers as control plants without clip cages $([\bar{X} \pm$ SEM $]$ control: $279 \pm 15$, clip caged: $274 \pm 25, P \gg .05$; see also Lehtilä and Strauss 1999). In addition, empty clip cages were not found to induce resistance in wild radish plants (Agrawal 1999b, 2000).

Seeds from experimental plants were collected and counted after plant senescence. Effects of herbivory on seed set are reported elsewhere (Agrawal et al. 1999a). Mean mass of individual seeds was calculated for each plant by randomly extracting individual seeds from 10-25 seed pods and weighing them to the microgram using a Mettler-Toledo UMT-2 balance (Hightstown, N.J.). Effects of family and herbivory on seed mass were assessed using a mixed-model ANOVA, with family as the random effect and herbivory as the fixed effect. All analyses were performed using the MGLH routine in SYSTAT version 7.0 for MS Windows (Wilkinson 1997) with Type III sums of squares.

To examine the effects of maternal herbivory on seedling characteristics, resistance to herbivores, and fitness, I conducted a field experiment. Eight to 10 seeds from each of 61 maternal plants within eight grandmaternal families (a total of 500 plants) were sown in a completely randomized design in a plowed field at the University of California student experimental farm (Davis, Calif.). The eight grandmaternal families were chosen because they spanned the full range of under- to overcompensation for herbivory (Agrawal et al. 1999a). Although this is a pseudorandom sample of the entire population, it is considered as a fixed effect for subsequent analyses because the range of compensating families are equally represented. The seeds were watered once before seedling emergence, and the plot was not further irrigated or weeded. Very dense weeds established early in the season. As an initial measurement of fitness, seedling emergence was monitored twice weekly for the first month of the experiment. For each of the 61 maternal families, the percentage of seedlings that emerged was calculated. Effects of maternal environment (with or without herbivory; fixed effect) and grandmaternal origin (fixed effect) on percentage seedling emergence in the field were analyzed using two-way ANOVA. Seed mass was used as a covariate because it may have affected seedling vigor and thus emergence and establishment. Data for percentage emergence were logit transformed for analyses to improve the normal distribution (Trexler and Travis 1993).
In a complementary analysis, I examined the effect of seed mass on seedling emergence using logistic regression. Here, emergence of individual plants was the response variable. This analysis treated each seed as independent and was strictly used to examine the relationship between seed mass and emergence.

At approximately the four-leaf stage, an unidentified virus infected many of the plants and caused the leaves to curl and considerably thicken. Infection was scored as present or absent. For each of the maternal families, the percentage of plants infected was calculated. Effects of maternal environment (with or without herbivory; fixed effect) and grandmaternal origin (fixed effect) on incidence of the virus were analyzed with ANOVA, with seed mass used as a covariate in the analysis. Seed mass was used as a covariate because it may have affected seedling size and vigor and therefore infection level. Data for percentage emergence and percentage plants infected with the virus were logit transformed for analyses to improve the normal distribution. Here again, I conducted an additional analysis using logistic regression to establish the direct relationship between seed mass and infection.

Several other seedling characters were measured on each plant (in units per plant): number of black necrotic lesions (typically indicative of attack by a pathogen), number of feeding pits by an unknown herbivore, and number of aphids. These plant attackers were treated as nonindependent and were included together in a multivariate analysis. As an indicator of growth, I measured the number of expanded leaves 1 mo after seedling emergence. Plant phenology and male seed-siring success were estimated by the number of open flowers per plant $2 \mathrm{wk}$ after the first open flower was observed. Ashman et al. (1993) found that early season flower number was strongly positively associated with male fitness (seed-siring ability) for populations of wild radish in Davis, California. At the end of the season, total fruit mass was measured as an indicator of female fitness. Fruit mass is a good predictor of the number of seeds produced $\left(N=624, r^{2}=0.80, P<.05\right.$; combined data from Agrawal 1998, 1999b). The three measures of plant performance (early season growth, flowers, and seed set) were treated as nonindependent in a multivariate analysis.

A separate greenhouse experiment was conducted to examine the effects of herbivory on maternal plants on the number of trichomes (a putative defensive character) on the progeny. One or two seeds from each of 35 maternal plants (within six grandmaternal families) were weighed and planted in the greenhouse. When the first true leaves were fully expanded, I cut out a $2-\mathrm{cm}^{2}$ disk near the apex of each leaf using a cork borer. I counted the number of trichomes on the top and bottom of the leaf disks and multiplied the density of trichomes by the total area of 
Table 1: Expected mean squares calculations for ANOVAs with grandmaternal family (fixed effect, eight levels), maternal environment (fixed effect, two levels), and maternal family (random effect, 61 levels) as main effects

\begin{tabular}{ll}
\hline Factor & \multicolumn{1}{c}{ Expected mean squares } \\
\hline Grandmaternal family & $\sigma^{2}+\sigma_{\mathrm{F}(\mathrm{G} \times \mathrm{M})}^{2}+122 \theta^{2}{ }_{\mathrm{G}}$ \\
Maternal environment & $\sigma^{2}+\sigma_{\mathrm{F}(\mathrm{G} \times \mathrm{M})}^{2}+488 \theta^{2}{ }_{\mathrm{M}}$ \\
$\mathrm{G} \times \mathrm{M}$ & $\sigma^{2}+61 \theta_{\mathrm{G} \times \mathrm{M}}^{2}+\sigma_{\mathrm{F}(\mathrm{G} \times \mathrm{M})}^{2}$ \\
Maternal family $(\mathrm{G} \times \mathrm{M})$ & $\sigma^{2}+\sigma_{\mathrm{F}(\mathrm{G} \times \mathrm{M})}$ \\
Error & $\sigma^{2}$ \\
\hline
\end{tabular}

Note: Grandmaternal family is tested over maternal family $(G \times M)$; maternal environment is tested over maternal family $(G \times M)$; grandmaternal family $\times$ maternal environment is tested over maternal family $(G \times M)$; maternal family $(G \times M)$ is tested over error. $G=$ grandmaternal family; $\mathrm{M}=$ maternal environment; $\mathrm{F}=$ maternal family. Parentheses represent nesting. Seed mass was entered as a covariate. Here, $\sigma^{2}$ with a subscript represents the variance due to subscripted effect when at least one of those is a random effect; $\sigma^{2}$ with no subscript represents the error variance. The $\theta^{2}$ represent the variance due to the subscripted effects when all of the effects noted are fixed.

the leaf (measured by a digital portable area meter, Li-Cor 3000, Lambda Instruments, Lincoln, Nebr.) to estimate the total number of trichomes on the leaves.

Effects of grandmaternal family (fixed effect), maternal environment (i.e., herbivory treatment; fixed effect), maternal family (nested within grandmaternal family by maternal environment interaction; random effect), and seed mass (covariate) on seedling characters were analyzed using mixed-model (M)ANOVAs (see fig. 1). Effects of grandmaternal family, maternal environment, and grandmaternal family by maternal environment interaction were tested using the maternal family nested in the grandmaternal family by treatment interaction mean squares and degrees of freedom in the denominator (see expected mean squares in table 1 ).

\section{Results}

The effects of herbivory on individual seed mass varied by family, with five families having greater seed mass and eight families having lower seed mass than controls when plants were damaged by caterpillars (table 2; fig. 2). This result indicates that there was genetic variation for effects of herbivory on seed mass. The maximum positive and negative effects of herbivory on seed mass were of equal magnitude, with up to a $50 \%$ increase or decrease in seed mass associated with herbivory, depending on the family (fig. 2).

Overall, plants that emerged came from seeds that were 9\% heavier than seeds that did not result in an established plant (logistic regression: $\chi^{2}=6.262, P=.015$; fig. 3). Leaf herbivory to maternal plants did not directly affect the percentage of emerged seedlings within each maternal family, grandmaternal family had no effect on emergence, and there were no interactions (all $F<1.5$, all $P>.35$ ).

In the greenhouse experiment to examine effects of herbivory on trichome number in the progeny, I found no significant main effect of maternal environment on trichome number. However, grandmaternal families showed high levels of variation for their response to herbivory, with some families more than doubling the number of trichomes on leaves of the progeny of damaged plants and other families showing a $40 \%$ reduction in leaf trichomes in the progeny of damaged plants (table 3; fig. 4). Seed mass (and subsequent leaf area) did not explain the differences in the number of trichomes (table 3).

Herbivory on maternal plants and seed mass all influenced the probability that plants (offspring) within a maternal family would be infected with the leaf curl virus in the field (table 4; fig. 5). The logistic regression analysis confirmed the ANOVA, with seed mass being positively associated with probability of infection $\left(\chi^{2}=3.767\right.$, $P=.052)$. Seedlings from damaged mothers were $25 \%$ more likely to be infected than seedlings from undamaged mothers.

There was evidence for genetic variation in constitutive resistance to the three other abundant plant parasites (tables 5,6 ). There were significant effects of grandmaternal family for number of feeding pits created by an unknown herbivore and number of aphids per plant. Although herbivory on maternal plants did not directly affect resistance to the plant parasites, seed mass was significantly correlated with the number of pits and aphids per plant and marginally correlated with the number of lesions per plant (table 6; fig. 6). Given that maternal environment did affect seed mass (table 2; fig. 2), there is an indirect effect of maternal environment on resistance of the offspring to various parasites. The relationship between seed mass and resistance to the parasites was negative. In other words, larger seeds produced plants that were less resistant to parasites (fig. 6).

Table 2: Effects of maternal environment (herbivory or no herbivory; fixed effect) and family (random effect) on mean individual seed mass

\begin{tabular}{lrrcc}
\hline Source & $\mathrm{df}$ & $\mathrm{ms}$ & $F$ & $P$ \\
\hline Maternal environment & 1 & $1,181,758.338$ & 1.039 & .328 \\
Family & 12 & $1,103,450.354$ & 2.446 & .010 \\
Family $\times$ maternal & & & & \\
$\quad$ environment & 12 & $1,137,590.390$ & 2.522 & .008 \\
Error & 67 & $451,061.148$ & $\ldots$ & $\ldots$ \\
\hline
\end{tabular}

Note: In this mixed-model ANOVA, the $F$ ratio for the maternal environment was calculated using the maternal environment by family interaction $\mathrm{df}$ and $\mathrm{ms}$ in the denominator; the family and maternal environment by family interaction was calculated using the error $\mathrm{df}$ and $\mathrm{ms}$ in the denominator. 


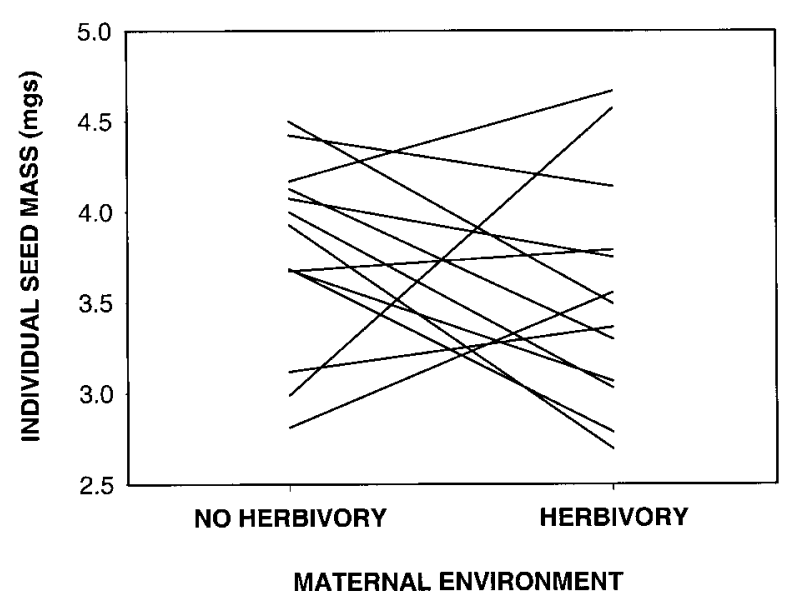

Figure 2: Reaction norm plot for the effect of maternal environment (no herbivory or herbivory) on mean mass of individual seeds per plant of 13 families of wild radish. Each line represents a family in which three to five plants were in each environment and many seeds were weighed from each plant.

Components of plant fitness were influenced by grandmaternal and maternal family and by seed mass (tables 5, 7). In addition, there was a marginal grandmaternal family by treatment interaction $(P=.055)$, suggesting that herbivory on maternal plants (maternal environment) affected fitness components in some families, irrespective of seed mass (fig. 7). In univariate analyses, this interaction term was equally weak for effects on number of leaves per plant, flowers, and fruit mass (table 7). Maternal effects, including both those that were correlated with seed mass and those that were not, dissipated as plants grew, with the strongest effects detectable only early in the season.

\section{Discussion}

\section{Effects of Herbivory on Seed and Seedling Characters}

Many biotic and abiotic factors are known to affect seed set of plants. For example, herbivory may affect the quantity and quality of seeds. Seed mass variation is ubiquitous, and its consequences have been well studied in wild radish plants (Stanton 1984, 1985; Mazer 1987). Although seed mass may vary within individual plants, biotic and abiotic effects on seed mass were previously thought to be relatively small compared to effects on seed number (Harper et al. 1970; Harper 1977; Weiner et al. 1997). Constancy in seed mass was thought to come at the expense of seed number. There is a weak negative phenotypic correlation, however, between seed number and seed mass in the wild radish system $\left(r^{2}=0.054, P<.001\right.$; data from Agrawal et al. 1999a). In addition, several studies have shown that folivory can result in increases or decreases in mean mass of individual seeds (Maun and Cavers 1971a, 1971b; Hendrix 1979; Lee and Bazzaz 1980; Crawley and Nachapong 1985; Wulff 1986). I found that the effects of herbivory on seed mass depended on maternal family. Effects of herbivory were as large as family effects and were equal in terms of magnitude in both the positive and negative direction (fig. 2). This suggests that there is genetic variation for maternal effects, a necessary but rarely quantified aspect of the evolution of maternal effects (Schmitt et al. 1992; Platenkemp and Shaw 1993; reviewed in Donohue and Schmitt 1998).

In addition to effects of herbivory on seed quantity and mass, herbivory may also alter seed viability (Marquis 1984; Murega and Khaemba 1985; Simmons and Yeargan 1990; Karban and Lowenberg 1992) and concentrations of primary (Burton et al. 1995) and secondary metabolites in seeds (Lammerink et al. 1984). For example, nitrogen, protein, and carbon concentrations may be lower in seeds from damaged plants, and these effects may alter seedling vigor, competitive ability, and resistance to herbivores. In a companion study (Agrawal et al. 1999c), however, I found no evidence that herbivory affected the total nitrogen or carbon composition of seeds. Secondary metabolite composition may also be altered in seeds of damaged versus control plants (e.g., Lammerink et al. 1984). Glucosinolates are an important class of sulfur containing mustard oil glycosides that have been extensively studied and are thought to be involved in plant resistance against vertebrates, invertebrates, and microorganisms (Chew 1988; Louda and Mole 1992; Giamoustaris and Mithen 1995). I found that glucosinolate profiles shifted in seeds from damaged plants compared with those from undamaged plants, and this was not variable between plant families

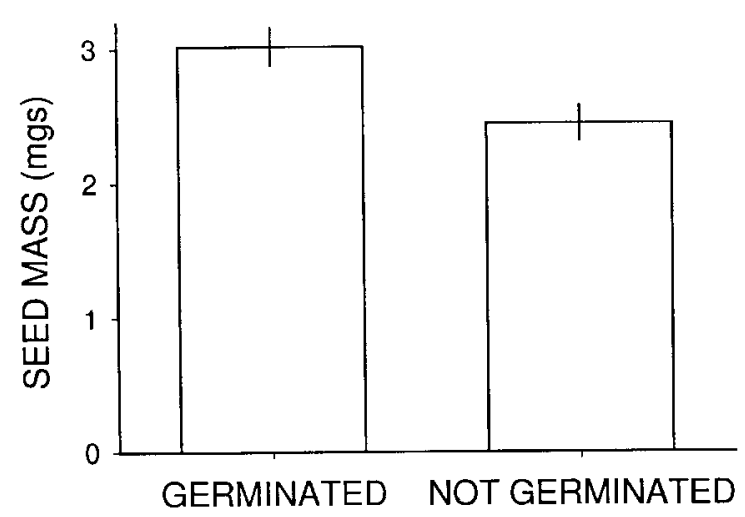

Figure 3: Mean individual seed mass for seedlings that did and did not emerge in the field. Bars are $\bar{X} \pm$ SEM. 
Table 3: Effects of grandmaternal family (fixed effect), maternal environment (herbivory or no herbivory; fixed effect), maternal family (random effect), and seed mass (covariate) on the number of setose trichomes on leaves

\begin{tabular}{lrrrc}
\hline Source & df & \multicolumn{1}{c}{$\mathrm{ms}$} & \multicolumn{1}{c}{$F$} & $P$ \\
\hline Grandmaternal family & 5 & $119,481.251$ & 1.579 & .205 \\
Maternal environment & 1 & $37,707.247$ & .498 & .487 \\
G $\times$ M & 5 & $240,396.449$ & 3.178 & .025 \\
Maternal family & & & & \\
$\quad(G \times \mathrm{M})$ & 23 & $75,648.998$ & 1.346 & .257 \\
Seed mass & 1 & $57,618.500$ & 1.025 & .324 \\
Error & 19 & $56,187.687$ & $\ldots$ & $\ldots$ \\
\hline
\end{tabular}

Note: Expected mean squares calculations are given in table 1. G = grandmaternal family; $\mathrm{M}=$ maternal environment.

(Agrawal et al. 1999c). Generally, I found that indole and aliphatic glucosinolates and the total number of glucosinolate peaks declined in seeds from damaged plants compared with controls, whereas hydroxylated glucosinolates increased in seeds in response to foliar herbivory. It is not known which classes of glucosinolates have antiherbivore properties in seeds; however, it is known that herbivory generally results in foliar induction of only indole glucosinolates (Koritsas et al. 1991; Bodnaryk 1992; Bodnaryk and Rymerson 1994; Agrawal et al. 1999a).

Seed glucosinolates are affected by many factors and are known to be primarily maternally inherited (Haughn et al. 1991; Magrath and Mithen 1993). In addition, seed chemistry determines the glucosinolate profile of seedlings and in some cases the resistance of seedlings to herbivores (Glen et al. 1990). Rapid-cycling Brassica that were infested with a nonvertically transmitted virus produced seeds with a higher glucosinolate concentration than uninfected plants (Shattuck 1993). Lammerink et al. (1984) showed that mustard plants infested with aphids produced seeds with higher total glucosinolate concentrations than uninfested plants. However, wilting of the plants, which may be caused by excessive aphid feeding, is also known to cause increased seed glucosinolate content (Milford and Evans 1991; Jensen et al. 1996). In this study, maternal plants were at no time water stressed and were fed on only by leaf-chewing caterpillars. Thus, effects of herbivory on seed chemistry were not likely due to water stress.

In some of the grandmaternal families, herbivory on the maternal plants caused progeny to have increased numbers of trichomes compared with the undamaged maternal plants (fig. 4). In other grandmaternal families, trichomes declined on the progeny of damaged maternal plants compared with the undamaged maternal plants. Setose trichomes may have many functions, including creating a boundary layer, functioning in gas exchange, and so forth (Woodman and Fernandes 1991; Ripley et al. 1999), and are a putative defense of plants in the Bras- sicaceae. In Brassica rapa, plants that are closely related to Raphanus raphanistrum, lines selected for high densities of trichomes had reduced leaf area consumed by Pieris rapae larvae compared with plants selected for low densities of trichomes (Ågren and Schemske 1993). Thus, like the effects on seed mass, there is genetic variation for the maternal effects of herbivory on leaf trichomes, which is involved in plant resistance to herbivores.

Maternal environment has also been shown to be important in the chemical phenotypes of plants. In the resinous shrub Diplacus aurantiacus, quantitative genetic studies showed that maternal effects explained $21 \%$ of the variance in resin production, which is thought to be important in resistance against specialist butterfly larvae (Han and Lincoln 1994, 1997).

\section{Effects of Herbivory on Offspring Resistance to Parasites}

Both genetic and environmental effects determine the resistance of progeny to parasites. For example, I found that grandmaternal and/or maternal family explained significant variation in plant resistance to pathogenic lesions, a leaf-chewing herbivore, and aphids. This familial variation is likely to be genetically based, as maternal effects on seed mass were controlled for and the original seeds used in this experiment were obtained from plants growing in a common greenhouse (unmanipulated) for two generations. In a companion study, I found that herbivory on the maternal plant by Pieris caterpillars, irrespective of its effects on seed mass, caused the offspring to be more resistant to herbivory by Pieris caterpillars in greenhouse

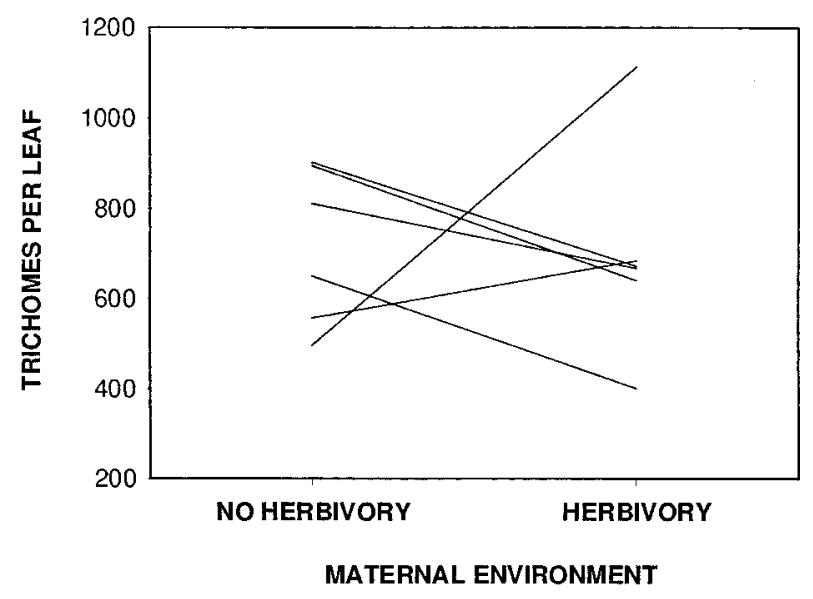

Figure 4: Reaction norm plot for the effect of maternal environment (no herbivory or herbivory) on the number of trichomes per leaf in progeny from six grandmaternal families of wild radish. Each line represents a family in which three to five maternal plants were in each environment. 
Table 4: Effects of grandmaternal family (fixed effect), maternal environment (herbivory or no herbivory; fixed effect), and seed mass (covariate) on percentage of the plants infected with a leaf curl virus

\begin{tabular}{lrccc}
\hline Source & df & \multicolumn{1}{c}{$\mathrm{ms}$} & \multicolumn{1}{c}{$F$} & $P$ \\
\hline Grandmaternal family & 7 & 3.140 & 1.612 & .158 \\
Maternal environment & 1 & 8.417 & 4.319 & .044 \\
G $\times$ M & 7 & 1.654 & .849 & .554 \\
Seed mass & 1 & 7.771 & 3.988 & .052 \\
Error & 43 & 1.949 & $\ldots$ & $\ldots$ \\
\hline
\end{tabular}

Note: Seed mass was positively associated with infection. In this ANOVA, the error $\mathrm{df}$ and $\mathrm{ms}$ were used in the denominator to calculate all the $F$ ratios. $\mathrm{G}=$ grandmaternal family; $\mathrm{M}=$ maternal environment.

experiments (Agrawal et al. 1999c). Caterpillars grew 20\% less on seedlings from damaged mothers compared with caterpillars on seedlings from undamaged mothers. These data provide evidence for transgenerational induction of defenses when seedlings from caterpillar-damaged mothers were challenged with caterpillars. Conversely, in the field experiment, herbivory on the maternal plant decreased progeny resistance to virus. It is possible that, because parent plants were not exposed to the virus (only caterpillar herbivory), resistance to virus was relaxed. In other words, there may be some level of specificity in transgenerational induced plant resistance. Caterpillar damage is followed by induced resistance to caterpillars within a generation (i.e., Agrawal 2000) and induced resistance to caterpillars across generations (Agrawal et al. 1999c); perhaps virus infestation would be followed by transgenerational resistance to the virus (see below for an example). However, I found no increase in resistance to the virus, and actually found increased susceptibility to the virus following herbivory. There is mounting evidence for trade-offs between induced plant resistance to herbivores and pathogens (Agrawal et al. 1999b; Felton et al. 1999; Thaler et al. 1999). It appears that such trade-offs also occur as maternal effects of induction across generations.

Resistance characters of progeny, other than resistance to the virus, were not directly affected by herbivory on the maternal plant. Seed mass, however, did negatively correlate with resistance to all of the plant parasites. Here, resistance was operationally defined as the number of aphids, pits, or lesions per plant. When resistance was defined as the number of these parasites on a per leaf basis, I found no effect of seed mass on aphids or lesions (data not shown), but there was still a positive correlation of seed mass and pits. Because herbivory on the maternal plant affected seed mass, positively in some families and negatively in other families, herbivory caused a maternal effect that indirectly affected resistance to parasites. Overall, herbivory can alter offspring quality such that there are direct and indirect consequences for the progeny's resistance to several parasites.

A few other studies have examined the effects of parasitism or the threat of predation on the defensive phenotype of offspring (Agrawal et al. 1999c). Systemic acquired resistance (SAR) of plants to pathogens is a parallel phenomenon to induced resistance of plants to herbivores; plants initially infected with pathogenic fungi, bacteria, or viruses subsequently become more resistant to a variety of pathogens (Kuć 1982). Roberts (1983) showed that tobacco plants (Nicotiana tabacum var. Samsun NN) inoculated with tobacco mosaic virus (TMV, Tobamovirus sp.) induced SAR in the selfed progeny of the infected plants compared with the progeny of uninfected plants. Mean lesion diameter (an indicator of plant susceptibility to the virus) in TMV-inoculated progeny was 38\% smaller on plants from infected mothers compared with the progeny of uninfected mothers. In another study of tobacco plants (N. tabacum var. Ky 14), Tuzun and Kuć (1987) found that SAR induced by the blue mold pathogen (Peronospora tabacina) did not transfer to the offspring via seeds. However, they did find that plants derived from tissue culture from various plant parts of induced plants were systemically protected against subsequent challenges with $P$. tabacina.

Transgenerational effects of predation risk have also been reported in animals. Induction of some morphological defenses (pointy helmets in water fleas, Daphnia cucullata, and spines in rotifers, Brachionus calyflorus) are induced in the offspring of parents exposed to waterborne

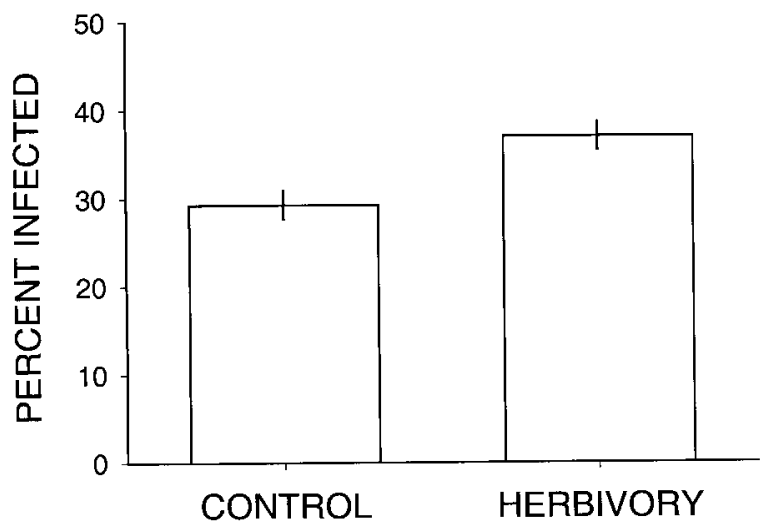

MATERNAL ENVIRONMENT

Figure 5: Effects of maternal parent environment, no herbivory (control), and herbivory on percent of the seedlings infected by a virus. Plant families did not show variation for the effect of maternal environment on infection (table 4). Bars are means adjusted for the seed mass covariate \pm SEM. 
Table 5: Effects of grandmaternal family (fixed effect), maternal environment (herbivory or no herbivory; fixed effect), maternal family (random effect), and seed mass (covariate) on three plant parasites and three fitness components of wild radish (MANOVA analysis)

\begin{tabular}{|c|c|c|c|c|c|c|c|c|}
\hline \multirow[b]{2}{*}{ Source } & \multicolumn{4}{|c|}{ Herbivores } & \multicolumn{4}{|c|}{ Plant fitness components } \\
\hline & df & Wilks's $\lambda$ & $F$ & $P$ & df & Wilks's $\lambda$ & $F$ & $P$ \\
\hline Grandmaternal family & 21,124 & .375 & 2.403 & .002 & 21,124 & .500 & 1.613 & .056 \\
\hline Maternal environment & 3,43 & .977 & .343 & .794 & 3,43 & .937 & .968 & .417 \\
\hline $\mathrm{G} \times \mathrm{M}$ & 21,124 & .633 & 1.021 & .444 & 21,124 & .499 & 1.618 & .055 \\
\hline Maternal family & & & & & & & & \\
\hline$(\mathrm{G} \times \mathrm{M})$ & 135,1121 & .714 & .987 & .528 & 135,977 & .614 & 1.282 & .022 \\
\hline Seed mass & 3,374 & .951 & 6.382 & $<.001$ & 3,326 & .958 & 4.745 & .003 \\
\hline
\end{tabular}

Note: Expected mean squares calculations are given in table $1 . \mathrm{G}=$ grandmaternal family; $\mathrm{M}=$ maternal environment.

chemical cues of their predators (Gilbert 1967; Agrawal et al. 1999c). When pregnant females of the viviparous lizard Pseudemoia pagenstecheri were exposed to scents of a predatory snake, the offspring were heavier, had longer tails, and were much more responsive (tongue flicking) than offspring from control mothers (Shine and Downes 1999). Each of these antipredatory responses may increase the survival of offspring in environments with predators.

\section{Effects of Herbivory on Offspring Growth}

In this study, both genetic and environmental factors contributed to components of plant fitness. Grandmaternal and maternal family contributed to variation in early season growth and number of flowers produced early in the reproductive phase. Herbivory on maternal plants affected progeny reproduction through a genotype by environment interaction for effects of herbivory and family on fitness components (table 5). This key result suggests that maternal effects imposed by herbivory may be subject to natural selection.

Seed mass, which was strongly influenced by maternal environment, also influenced components of plant fitness. As is often reported, effects of seed mass were strongest in early season growth (Weiner et al. 1997). Seed mass was a strong predictor of seedling emergence and the number of leaves plants produced, but it had a less detectable effect on flower or fruit production. This is surprising, given that other studies of wild radish have found a significant effect of seed mass on components of adult fitness (Stanton 1984; Mazer 1987). Like these previous studies, the plants in my experiment had a high level of competition from other plants. However, water was generally not a limiting resource in this El Niño year (i.e., very heavy rains in northern California), perhaps attenuating the effect of seed mass variation even in the highly competitive environment. Another explanation for the lack of effect of seed mass on components of adult fitness is given below.

Two other studies have examined the consequences of herbivory for progeny success. Crawley and Nachapong (1985) showed that ragwort plants protected from cinnabar moth caterpillar herbivory produced larger seeds than plants that were defoliated and produced "regrowth seeds" later in the season. They also demonstrated that transgenerational effects of herbivory reduced seedling establishment but only in competitive environments. Weiner et al. (1997) asked similar questions for seeds of spotted knapweed but found that seed mass was unaffected by herbivory or fertilization of the maternal plant. Maternal identity and seed mass did have short-lived effects on components of seedling fitness. However, these effects quickly dissipated, and no effects of herbivory per se were detected in the reproductive characters of the next generation.

In similar experiments with animals, induction of some morphological defenses (neckteeth) in Daphnia pulex caused a maternal effect whereby offspring of induced $D$. pulex were larger than offspring of uninduced individuals (Tollrian 1995b). Although large size is typically associated

Table 6: Effects of grandmaternal family (fixed effect) and seed mass (covariate) on resistance to specific plant parasites (univariate ANOVAs)

\begin{tabular}{|c|c|c|c|c|c|c|c|}
\hline \multirow[b]{2}{*}{ Source } & \multirow[b]{2}{*}{ df } & \multicolumn{2}{|c|}{ Lesions } & \multicolumn{2}{|c|}{ Pits } & \multicolumn{2}{|c|}{ Aphids } \\
\hline & & $F$ & $P$ & $F$ & $P$ & $F$ & $P$ \\
\hline Grandmaternal family & 7,45 & .90 & .515 & 2.81 & .016 & 3.85 & .002 \\
\hline Seed mass & 1,378 & 3.27 & .071 & 12.89 & $<.001$ & 4.47 & .035 \\
\hline
\end{tabular}

Note: Univariate ANOVAs are only shown where the MANOVA $P<.1$. Expected mean squares calculations are given in table 1 . 

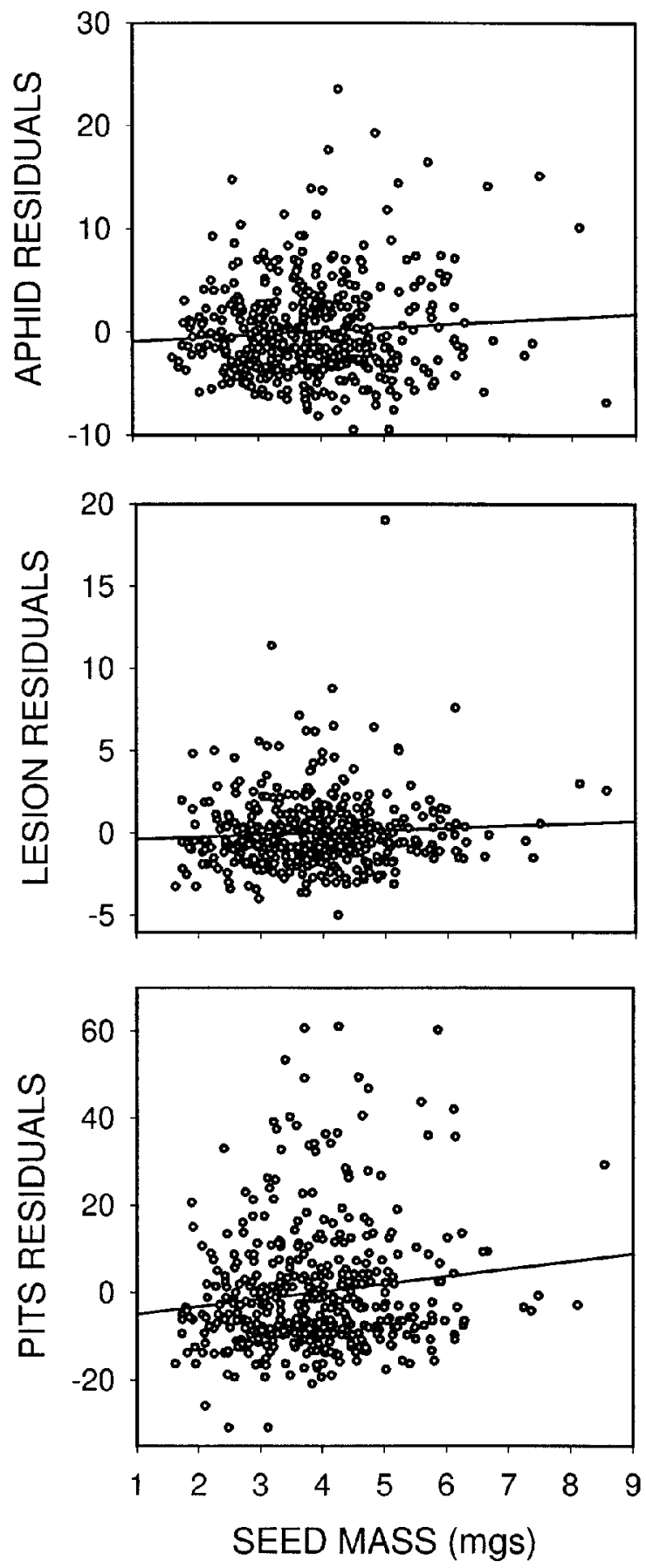

Figure 6: The effects of seed mass on the number of aphids, pathogenic lesions, and feeding pits per plant plotted as seed mass versus the residuals of the ANOVA model, including grandmaternal family, maternal environment, grandmaternal family by maternal environment interaction, and maternal family nested in grandmaternal family by maternal environment interaction. The residuals provide an estimate of the effect of seed mass on the number of aphids, pathogenic lesions, and feeding pits with the other factors removed. with faster growth and higher reproductive potential in $D$. pulex (as in plants), large size in the early instars increased probability of encounters with predators and vulnerability to attack (Tollrian 1995a). Similar results have been reported in plant-herbivore systems, with larger seeds being more heavily attacked than smaller seeds (Mitchell 1977;
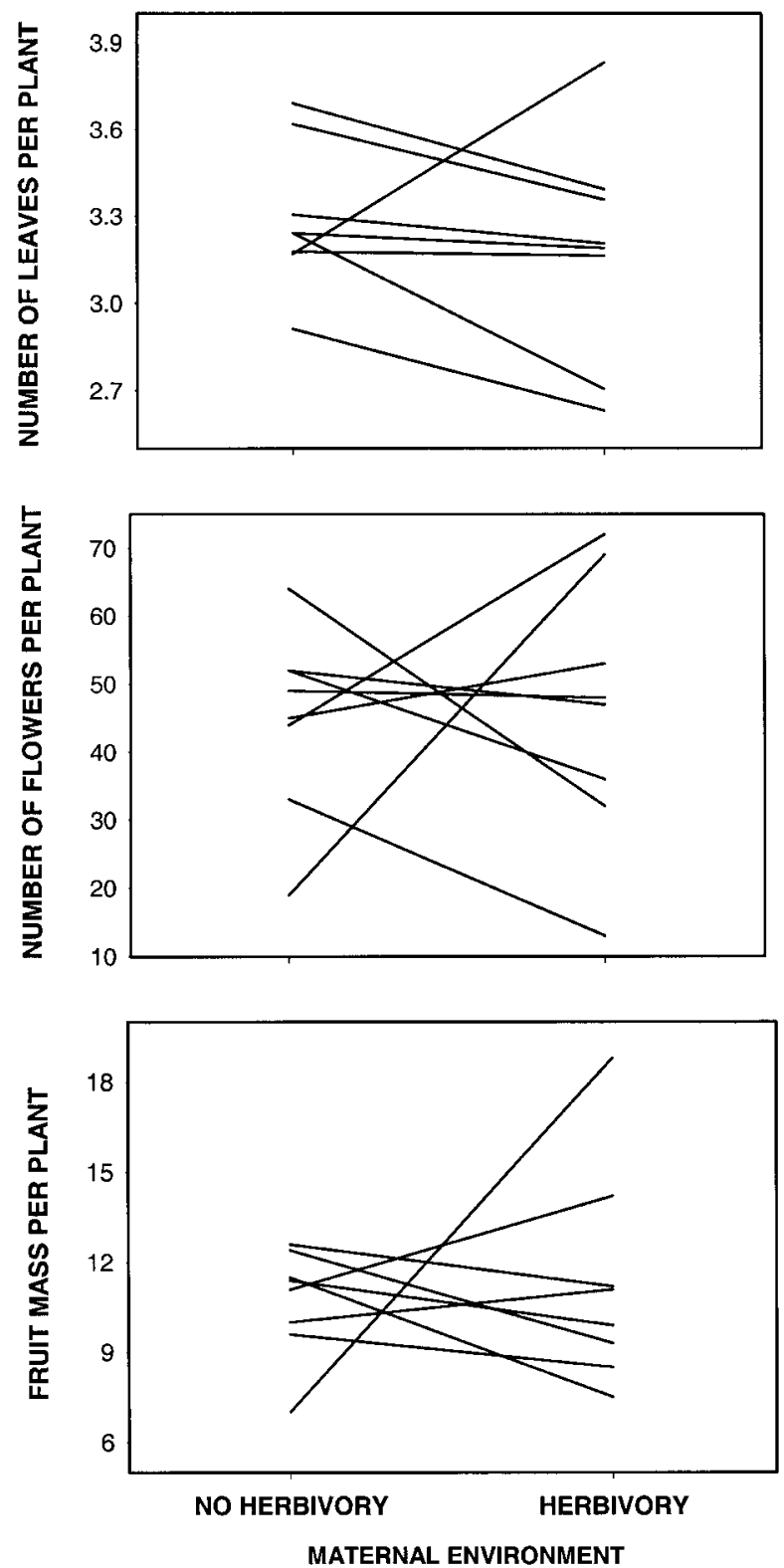

Figure 7: Reaction norm plot for the effect of maternal environment (no herbivory or herbivory) on the number of leaves and flowers per plant and final fruit mass in progeny from eight grandmaternal families of wild radish. Each line represents a family with three to five maternal plants in each environment. Means are adjusted for the seed mass covariate. 
Table 7: Effects of grandmaternal family (fixed effect), maternal family (random effect), and seed mass (covariate) on specific fitness components (univariate ANOVAs)

\begin{tabular}{|c|c|c|c|c|c|c|c|}
\hline \multirow[b]{2}{*}{ Source } & \multirow[b]{2}{*}{$\mathrm{df}$} & \multicolumn{2}{|c|}{ Leaves } & \multicolumn{2}{|c|}{ Flowers } & \multicolumn{2}{|c|}{ Fruit mass } \\
\hline & & $F$ & $P$ & $F$ & $P$ & $F$ & $P$ \\
\hline Grandmaternal family & 7,45 & 2.72 & .019 & 1.30 & .272 & .760 & .623 \\
\hline $\mathrm{G} \times \mathrm{M}$ & 7,45 & 1.61 & .157 & 1.82 & .106 & 1.824 & .106 \\
\hline Maternal family & & & & & & & \\
\hline$(\mathrm{G} \times \mathrm{M})$ & 45,328 & 1.402 & .052 & 2.063 & $<.001$ & 1.121 & .284 \\
\hline Seed mass & 1,328 & 13.62 & $<.001$ & 1.45 & .230 & 2.460 & .118 \\
\hline
\end{tabular}

Note: Univariate ANOVAs are shown only where the MANOVA $P<.1$. Expected mean squares calculations are given in table $1 . \mathrm{G}=$ grandmaternal family; $\mathrm{M}=$ maternal environment.

Kelrick et al. 1986; Bailey and Polis 1987). My results support this finding; larger seeds turned into larger plants, which were more heavily attacked by herbivores and pathogens. In the end, there was no overall benefit or cost to having large seeds, perhaps because growth benefits were compromised by increased susceptibility to plant parasites. This calls attention to the familial variation in maternal effects observed; some families produced larger seeds when attacked by herbivores, while some families produced smaller seeds when attacked by herbivores. It is possible that this variation is maintained, in part, because of balancing selection. Although larger seeds may produce competitively superior plants, such plants may also be subject to greater levels of attack by herbivores and pathogens.

\section{Adaptive Maternal Effects?}

In the past, environmentally induced plasticity and maternal effects were thought to constrain adaptive evolution because phenotypic differences in individuals are, at least in part, uncoupled from genotypic differences (Falconer 1989; Kirkpatrick and Lande 1989). A more recent view has been that phenotypically plastic traits that affect fitness should themselves be subject to natural selection (e.g., Mousseau and Dingle 1991; Schmitt et al. 1992; Plantenkamp and Shaw 1993; Sultan 1996; Byers et al. 1997; Fox et al. 1997; Mousseau and Fox 1998; Thiede 1998). If so, then genetically determined levels of plasticity for traits such as maternal effects may be influenced by natural selection. The lag time between maternal environment (gene activation) and offspring phenotype (the target of selection) has the potential to increase or decrease the responses to natural selection (Kirkpatrick and Lande 1989), and only recently have studies begun to examine the evolutionary consequences of maternal effects (Schluter and Gustafsson 1993; Thiede 1998).

Little is currently known about the genetics of herbivore-induced defenses in plants and the maternal effects with which they are associated (Agrawal 1999a). There is a genetic basis for some of the maternal effects reported in this study, including effects on components of fitness. In addition, herbivory on the maternal plant affected resistance of progeny and fitness components through effects on seed mass, and there is strong evidence that there is genetic variation for how herbivory affects seed mass. Genetic variation in the effects of herbivory on seed mass may mediate effects on the competitive ability of offspring and the ability of offspring to resist plant parasites. Given that these effects are antagonistic, with larger seeds generally having greater competitive ability (Stanton 1984, 1985) and reduced resistance, selection may maintain variation in such maternal effects.

As for other forms of phenotypic plasticity, maternal effects can only be adaptive if environmental information in the maternal generation predicts the environmental conditions of progeny (Karban et al. 1999). In this study, I experimentally manipulated the maternal environment with controlled caterpillar herbivory. In the field, caterpillars were not a major pest of the plants. Therefore, a definitive test of the adaptive nature of maternal effects caused by herbivory will necessarily involve examining maternal effects and environmental correlations across years. For wild radish plants, caterpillar herbivory in the maternal generation directly increased the resistance of progeny to caterpillar herbivory (Agrawal et al. 1999c); if herbivore densities are correlated across years, maternally induced defenses of plants should be favored by natural selection.

\section{Acknowledgments}

This study would not have been possible without the patient advice of K. J. Rice. The project also greatly benefited from the input of R. Karban and the plant-insect discussion group at the University of California, Davis. I thank J. A. Rosenheim and S. Y. Strauss for loaning equipment. The initial phase of the project was conducted in collaboration with J. Kniskern and S. Y. Strauss. Many thanks to M. X. Van Horn who helped with logistics at the University of California, Davis, student experimental farm. R. 
J. Mercader helped with the fieldwork and counting trichomes. C. Alexander helped process the seed pods, and C. N. Klein and R. J. Mercader helped with weighing the seeds. F. Adler, J. Stueffer, J. Travis, and N. Willits provided statistical advice. Versions of the manuscript were improved by the comments of C. A. Black, J. Chase, J. A. Fordyce, J. D. Hoeksema, R. Karban, T. A. Mousseau, K. J. Rice, J. A. Rosenheim, J. A. Rudgers, M. L. Stanton, S. Y. Strauss, J. S. Thaler, J. Travis, N. Underwood, and an anonymous reviewer. This study was financially supported by the Center for Population Biology (University of California, Davis), Section of Population Biology (University of Amsterdam), Department of Botany (University of Toronto), and the U.S. National Science Foundation DEB9701109.

\section{Literature Cited}

Aarssen, L. W., and S. M. Burton. 1990. Maternal effects at four levels in Senecio vulgaris (Asteraceae) grown on a soil nutrient gradient. American Journal of Botany 77: 1231-1240.

Agrawal, A. A. 1998. Induced responses to herbivory and increased plant performance. Science (Washington, D.C.) 279:1201-1202.

- 1999a. Induced plant defense: evolution of induction and adaptive phenotypic plasticity. Pages 251-268 in A. A. Agrawal, S. Tuzun, and E. Bent, eds. Inducible plant defenses against pathogens and herbivores: biochemistry, ecology, and agriculture. American Phytopathological Society, St. Paul, Minn.

- 1999b. Induced responses to herbivory in wild radish: effects on several herbivores and plant fitness. Ecology 80:1713-1723.

- 2000. Specificity of induced resistance in wild radish: causes and consequences for two specialist and two generalist caterpillars. Oikos 89:493-500.

Agrawal, A. A., S. Y. Strauss, and M. J. Stout. 1999a. Costs of induced responses and tolerance to herbivory in male and female fitness components of wild radish. Evolution 53:1093-1104.

Agrawal, A. A., S. Tuzun, and E. Bent, eds. 1999b. Induced plant defense against pathogens and herbivores: biochemistry, ecology, and agriculture. American Phytopathological Society, St. Paul, Minn.

Agrawal, A. A., C. Laforsch, and R. Tollrian. 1999c. Transgenerational induction of defenses in animals and plants. Nature (London) 401:60-63.

Ågren, J., and D. W. Schemske. 1993. The cost of defense against herbivores: an experimental study of trichome production in Brassica rapa. American Naturalist 141: 338-350.

Arimoto, Y., Y. Homma, R. Yoshino, and S. Saito. 1991.
Generational succession of DL-alanine dodecyl ester hydrochloride-induced resistance to blast disease in rice plants. Annals of the Phytopathological Society of Japan 57:522-525.

Ashman, T. L., L. F. Galloway, and M. L. Stanton. 1993. Apparent vs. effective mating in an experimental population of Raphanus sativus. Oecologia (Berlin) 96: 102-107.

Bailey, K. H., and G. A. Polis. 1987. Optimal and centralplace foraging theory applied to a desert harvester ant, Pogonomyrmex californicus. Oecologia (Berlin) 72: 440-448.

Baldwin, I. T., and M. J. Karb. 1995. Plasticity in allocations of nicotine to reproductive parts in Nicotiana attenuata. Journal of Chemical Ecology 21:897-909.

Barbercheck, M. E., J. Wang, and I. S. Hirsh. 1995. Host plant effects on entomopathogenic nematodes. Journal of Invertebrate Pathology 66:169-177.

Bigger, D. S., and M. A. Marvier. 1998. How different would a world without herbivory be? Integrative Biology 1:60-67.

Bodnaryk, R. P. 1992. Effects of wounding on glucosinolates in the cotyledons of oilseed rape and mustard. Phytochemistry 31:2671-2677.

Bodnaryk, R. P., and R. T. Rymerson. 1994. Effect of wounding and jasmonates on the physico-chemical properties and flea beetle defence responses of canola seedlings, Brassica napus L. Canadian Journal of Plant Science 74:899-907.

Burton, J. W., D. W. Isreal, R. F. Wilson, and T. E. Carter. 1995. Effects of defoliation on seed protein concentration in normal and high protein lines of soybean. Plant and Soil 172:131-139.

Byers, D. L., G. A. J. Platenkamp, and R. G. Shaw. 1997. Variation in seed characters in Nemophila menziesii: evidence of a genetic basis for maternal effect. Evolution 51:1445-1456.

Chew, F. S. 1988. Biological effects of glucosinolates. Pages 156-181 in H. C. Cutler, ed. Biologically active natural products: potential use in agriculture. American Chemical Society, Washington, D.C.

Cipollini, M. L., and D. J. Levey. 1997. Secondary metabolites of fleshy vertebrate-dispersed fruits: adaptive hypotheses and implications for seed dispersal. American Naturalist 150:346-372.

Crawley, M. J., and M. Nachapong. 1985. The establishment of seedlings from primary and regrowth seeds of ragwort (Senecio jacobaea). Journal of Ecology 73: 255-262.

Donohue, K., and J. Schmitt. 1998. Maternal environmental effects in plants: adaptive plasticity? Pages 137-158 in T. A. Mousseau and C. W. Fox, eds. Maternal 
effects as adaptations. Oxford University Press, New York.

Dudley, S. A., and J. Schmitt. 1996. Testing the adaptive plasticity hypothesis: density-dependent selection on manipulated stem length in Impatiens capensis. American Naturalist 147:445-465.

Dussourd, D. E., K. Ubik, C. Harvis, J. Resch, J. Meinwald, and T. Eisner. 1988. Biparental defensive endowment of eggs with acquired plant alkaloid in the moth Utetheisa ornatrix. Proceedings of the National Academv of Sciences of the USA 85:5992-5996.

Falconer, D. S. 1989. Introduction to quantitative genetics. 3d ed. Wiley, New York.

Felton, G. W., K. L. Korth, J. L. Bi, S. V. Wesley, D. V. Huhman, M. C. Mathews, J. B. Murphy, C. Lamb, and R. A. Dixon. 1999. Inverse relationship between systemic resistance of plants to microorganisms and to insect herbivory. Current Biology 9:317-320.

Fox, C. W., M. S. Thakar, and T. A. Mousseau. 1997. Egg size plasticity in a seed beetle: an adaptive maternal effect. American Naturalist 149:149-163.

Giamoustaris, A., and R. Mithen. 1995. The effect of modifying the glucosinolate content of leaves of oilseed rape (Brassica napus ssp. oleifera) on its interaction with specialist and generalist pests. Annals of Applied Biology 126:347-363.

Gilbert, J. J. 1967. Asplanchna and postlateral spine induction in Brachionus calyciflorus. Archives für Hydrobiologie 64:1-62.

Glazebrook, J., E. E. Rogers, and F. M. Ausubel. 1997. Use of Arabidopsis for genetic dissection of plant defense responses. Annual Review of Genetics 31:547-569.

Glen, D. M., H. Jones, and J. K. Fieldsend. 1990. Damage to oilseed rape seedlings by the field slug Deroceras reticulatum in relation to glucosinolate concentrations. Annals of Applied Biology 117:197-208.

Han, K., and D. E. Lincoln. 1994. The evolution of carbon allocation to plant secondary metabolites: a genetic analysis of cost in Diplacus aurantiacus. Evolution 48: $1550-1563$.

Han, K. P., and D. E. Lincoln. 1997. The impact of plasticity and maternal effect on the evolution of leaf resin production in Diplacus aurantiacus. Evolutionary Ecology 11:471-484.

Harper, J. L. 1977. Population biology of plants. Academic Press, London.

Harper, J. L., P. H. Lovell, and K. G. Moore. 1970. The shapes and sizes of seeds. Annual Review of Ecology and Systematics 1:327-356.

Haughn, G. W., L. Davin, M. Giblin, and E. W. Underhill. 1991. Biochemical genetics of plant secondary metabolites in Arabidopsis thaliana: the glucosinolates. Plant Phvsiology 97:217-226.
Hendrix, S. D. 1979. Compensatory reproduction in a biennial herb following insect defloration. Oecologia (Berlin) 42:107-118.

Heppell, K. B., D. L. Shumway, and R. T. Koide. 1998. The effect of mycorrhizal infection of Abutilon theophrasti on competitiveness of offspring. Functional Ecology 12:171-175.

Janzen, D. H. 1971. Seed predation by animals. Annual Review of Ecology and Svstematics 2:465-492.

Jensen, B. D., A. O. Latunde-Dada, D. Hudson, and J. A. Lucas. 1998. Protection of Brassica seedlings against downy mildew and damping-off by seed treatment with CGA 245704, an activator of systemic acquired resistance. Pesticide Science 52:63-69.

Jensen, C. R., V. O. Mogensen, G. Mortensen, J. K. Fieldsend, G. F. J. Milford, M. N. Andersen, and J. H. Thage. 1996. Seed glucosinolate, oil and protein contents of field-grown rape (Brassica napus L.) affected by soil drying and evaporative demand. Field Crops Research 47: 93-105.

Karban, R., and I. T. Baldwin. 1997. Induced responses to herbivory. University of Chicago Press, Chicago.

Karban, R., and G. Lowenberg. 1992. Feeding by seed bugs and weevils enhances germination of wild Gossypium species. Oecologia (Berlin) 92:196-200.

Karban, R., A. A. Agrawal, J. S. Thaler, and L. S. Adler. 1999. Induced plant responses and information content about risk of herbivory. Trends in Ecology \& Evolution 14:443-447.

Kelrick, M. I., J. A. Macmahon, R. R. Parmenter, and D. V. Sisson. 1986. Native seed preferences of shrub-steppe rodents, birds and ants: the relationships of seed attributes and seed use. Oecologia (Berlin) 68:327-337.

Kirkpatrick, M., and R. Lande. 1989. The evolution of maternal characters. Evolution 43:485-503.

Koritsas, V. M., J. A. Lewis, and G. R. Fenwick. 1991. Glucosinolate responses of oilseed rape, mustard and kale to mechanical wounding and infestation by cabbage stem flea beetle (Psylliodes chrysocephala). Annals of Applied Biology 118:209-222.

Kuć, J. 1982. Induced immunity to plant disease. BioScience 32:854-860.

Lammerink, J., D. B. MacGibbon, and A. R. Wallace. 1984. Effect of the cabbage aphid (Brevicoryne brassicae) on total glucosinolate in the seed of oilseed rape (Brassica napus). New Zealand Journal of Agricultural Research 27:89-92.

Lee, T. D., and F. A. Bazzaz. 1980. Effects of defoliation and competition on growth and reproduction in the annual plant Abutilon theophrasti. Journal of Ecology 68:813-821.

Lehtilä, K., and S. Y. Strauss. 1999. Effects of foliar her- 
bivory on male and female reproductive traits of wild radish, Raphanus raphanistrum. Ecology 80:116-124.

Louda, S., and S. Mole. 1992. Glucosinolate chemistry and ecology. Pages 123-164 in G. A. Rosenthal and M. R. Berenbaum, ed. Herbivores: their interactions with secondary plant metabolites. The chemical participants. $2 \mathrm{~d}$ ed. Vol. 1. Academic Press, San Diego, Calif.

Magrath, R., and R. Mithen. 1993. Maternal effects on the expression of individual aliphatic glucosinolates in seeds and seedlings of Brassica napus. Plant Breeding 111: 249-252.

Maron, J. L. 1997. Interspecific competition and insect herbivory reduce bush lupine (Lupinus arboreus) seedling survival. Oecologia (Berlin) 110:284-290.

Marquis, R. J. 1984. Leaf herbivores decrease fitness of a tropical plant. Science (Washington, D.C.) 226:537-539.

- 1992. The selective impact of herbivores. Pages 301-325 in R. S. Fritz and E. L. Simms, eds. Plant resistance to herbivores and pathogens: ecology, evolution, and genetics. University of Chicago Press, Chicago.

Maun, M. A., and P. B. Cavers. 1971a. Seed production in Rumex crispus. I. The effects of removal of cauline leaves at anthesis. Canadian Journal of Botany 49: 1123-1130.

- $1971 b$. Seed production in Rumex crispus. II. The effects of removal of various proportions of flowers at anthesis. Canadian Journal of Botany 49:1841-1848.

Mazer, S. J. 1987. The quantitative genetics of life history and fitness components in Raphanus raphanistrum L. (Brassicaceae): ecological and evolutionary consequences of seed weight variation. American Naturalist 130:891-914.

Milford, G. F. J., and E. J. Evans. 1991. Factors causing variation in glucosinolates in oilseed rape. Outlook on Agriculture 20:31-38.

Mitchell, R. 1977. Bruchid beetles and seed packaging by Palo Verde. Ecology 58:644-651.

Mousseau, T. A., and H. Dingle. 1991. Maternal effects in insect life histories. Annual Review of Entomology 36: 511-534.

Mousseau, T. A., and C. W. Fox. 1998. Maternal effects as adaptations. Oxford University Press, New York.

Murega, T. N., and B. M. Khaemba. 1985. The effects of the infestation by red spider mites, Tetranychus sp. (Acarina: Tetranychidae) on the growth and yield components of cotton in eastern Kenya. Insect Science and Its Application 6:7-10.

Mutikainen, P., and L. F. Delph. 1996. Effects of herbivory on male reproductive success in plants. Oikos 75: 353-358.

Plantenkamp, G. A. J., and R. G. Shaw. 1993. Environmental and genetic maternal effects on seed characters in Neomophila menziesii. Evolution 47:540-555.
Quesada, M., K. Bollman, and A. G. Stephenson. 1995. Leaf damage decreases pollen production and hinders pollen performance in Cucurbita texana. Ecology 76: 437-443.

Ripley, B. S., N. W. Pammenter, V. R. Smith. 1999. Function of leaf hairs revisited: the hair layer on leaves Arctotheca populifolia reduces photoinhibition, but leads to higher leaf temperatures caused by lower transpiration rates. Journal of Plant Physiology 155:78-85.

Roach, D. A., and R. D. Wulff. 1987. Maternal effects in plants. Annual Review of Ecology and Systematics 18: 209-236.

Roberts, D. A. 1983. Acquired resistance to tobacco mosaic virus transmitted to the progeny of hypersensitive tobacco. Virology 124:161-163.

Rossiter, M. 1996. Incidence and consequences of inherited environmental effects. Annual Review of Ecology and Systematics 27:451-476.

Ryan, C. A. 1990. Protease inhibitors in plants: genes for improving defenses against insects and pathogens. Annual Review of Phytopathology 28:425-450.

Schluter, D., and L. Gustafsson. 1993. Maternal inheritance of condition and clutch size in the collared flycatcher. Evolution 47:658-667.

Schmitt, J., J. Niles, and R. D. Wulff. 1992. Norms of reaction of seed traits to maternal environments in Plantago lanceolata. American Naturalist 139:451-466.

Shattuck, V. I. 1993. Glucosinolates and glucosinolate degradation in seeds from turnip mosaic virus-infected rapid cycle Brassica campestris L. plants. Journal of Experimental Botany 44:963-970.

Shine, R., and S. J. Downes. 1999. Can pregnant lizards adjust their offspring phenotypes to environmental conditions? Oecologia (Berlin) 119:1-8.

Siegrist, J., D. Glenewinkel, C. Kolle, and M. Schmidtke. 1997. Chemically induced resistance in green bean against bacterial and fungal pathogens. Zeitschrift für Pflanzenkrankheiten und Pflanzenschutz 104:599-610.

Siemens, D. H., and T. Mitchell-Olds. 1998. Evolution of pest-induced defenses in Brassica plants: tests of theory. Ecology 79:632-646.

Simmons, A. M., and K. V. Yeargan. 1990. Effect of combined injuries from defoliation and green stink bug (Hemiptera: Pentatomidae) and influence of field cages on soybean yield and seed quality. Journal of Economic Entomology 83:599-609.

Stanton, M. L. 1984. Seed variation in wild radish: effect of seed size on components of seedling and adult fitness. Ecology 65:1105-1112.

- 1985. Seed size and emergence time within a stand of wild radish (Raphanus raphanistrum L.): the establishment of a fitness hierarchy. Oecologia (Berlin) 67: 524-531. 
Strauss, S. Y. 1997. Floral characters link herbivores, pollinators, and plant fitness. Ecology 78:1640-1645.

Strauss, S. Y., and A. A. Agrawal. 1999. Ecology and evolution of plant tolerance herbivory. Trends in Ecology \& Evolution 14:179-185.

Sultan, S. E. 1996. Phenotypic plasticity for offspring traits in Polygonum persicaria. Ecology 77:1791-1807.

Tallamy, D. W., D. P. Whittington, F. Defurio, D. A. Fontaine, P. M. Gorski, and P. W. Gothro. 1998. Sequestered cucurbitacins and pathogenicity of Metarhizium anisopliae (Moniliales: Moniliaceae) on spotted cucumber beetle eggs and larvae (Coleoptera: Chrysomelidae). Environmental Entomology 27:366-372.

Tallamy, D. W., P. M. Gorsky, and J. K. Burzon. 2000. Fate of male-derived cucurbitacins in spotted cucumber beetle females. Journal of Chemical Ecology 26:413-428.

Thaler, J. S., A. L. Fidantsef, S. S. Duffey, and R. M. Bostock. 1999. Tradeoffs in plant defense against pathogens and herbivores: a field demonstration using chemical elicitors of induced resistance. Iournal of Chemical Ecology 25:1597-1609.

Thiede, D. A. 1998. Maternal inheritance and its effect on adaptive evolution: a quantitative genetic analysis of maternal effects in a natural plant population. Evolution 52:998-1015.

Tollrian, R. 1995a. Chaoborus crystallinus predation on Daphnia pulex: can induced morphological changes balance effects of body size on vulnerability? Oecologia (Berlin) 101:151-155. 1995b. Predator-induced morphological defenses: costs, life history shifts, and maternal effects in Daphnia pulex. Ecology 76:1691-1705.

Trexler, J. C., and J. Travis. 1993. Nontraditional regression analyses. Ecology 74:1629-1637.

Tuzun, S., and J. Kuć. 1987. Persistence of induced systemic resistance to blue mold in tobacco plants derived via tissue culture. Phytopathology 77:1032-1035.

Weiner, J., S. Martinez, H. Mueller-Schaerer, P. Stoll, and B. Schmid. 1997. How important are environmental maternal effects in plants? a study with Centaurea maculosa. Journal of Ecology 85:133-142.

Wilkinson, L. 1997. SYSTAT. Version 7.0. SPSS, Inc., Chicago.

Woodman, R. L., and G. W. Fernandes. 1991. Differential mechanical defense: herbivory, evapotranspiration, and leaf hairs. Oikos 60:11-19.

Wulff, R. D. 1986. Seed size variation in Desmodium paniculatum. I. Factors affecting seed size. Journal of Ecology 74:87-98.

Zangerl, A. R., and C. E. Rutledge. 1996. The probability of attack and patterns of constitutive and induced defense: a test of optimal defense theory. American Naturalist 147:599-608.

Zhu, Q., W. Droge-Laser, R. A. Dixon, and C. Lamb. 1996. Transcriptional activation of plant defense genes. Current Opinion in Genetics \& Development 6:624-630.

Editor: Joseph Travis 